\title{
Da Colonização e da Emancipação do Pensamento
}

\section{Rodrigo Dantas}

1. Proposições e enunciados de pensamento nascem da história, lhe pertencem e sobre ela incidem à medida que necessariamente agem sobre as condições de compreensão, problematização, racionalização e comunicação do real. Idéias $e$ concepções de mundo não brotam simplesmente da mente de sujeitos sem história e sem sociedade, se dirigindo a um mundo abstrato de objetos sem história e sem contexto social: elas nascem da historicidade de um determinado modo de produção da vida pela própria vida, de uma determinada formação social. Como expressões ideais, como racionalizações dos múltiplos interesses, posições e perspectivas que nela se formam, sua multiplicidade reflete a multiplicidade dos interesses, forças, posições e perspectivas que se materializam e são capazes de manifestar-se no interior de uma época, de uma formação social determinada.

Idéias e concepções de mundo nascem, portanto, da historicidade de uma práxis concretamente determinada, seja como sua racionalização, sua auto-consciência, sua meta-narrativa, sua idealização, sua mistificação _ou, no limite, como sua problematização, sua crítica, sua desconstrução e sua transformação. Elas formulam, organizam e sistematizam o ponto de vista, o discurso e a racionalidade de uma práxis, de uma determinada experiência de ser, a que pertencem como sua expressão ideal, como sua reflexão, como sua própria auto-consciência. Elas agem, portanto, seja no sentido de refletir e racionalizar, em suas mais variadas dimensões, um determinado modo de produção pela própria vida, como expressões ideais das relações materiais dominantes e da ordem social de dominação que elas formam [1] _ seja no sentido de problematizá-la e, por essa problematização mesma, criar os conceitos, as práticas, as relações e os sujeitos que possam gerar as condições subjetivas e objetivas para sua transformação.

Como diria Antonio Gramsci, elas concorrem entre si na disputa pela hegemonia e pela contra-hegemonia na formação histórico-social dos regimes ideológicos, cognitivos, simbólicos e pedagógicos que configuram as próprias condições epistêmicas de produção, validação e legitimação dos enunciados, teorias e concepções de mundo; nesse sentido, ao concorrerem pela determinação das condições de compreensão da vida e do próprio mundo, elas concorrem pela determinação das condições de constituição dos sujeitos sociais, de suas práticas e de suas relações, de seu universo de interlocução e de suas próprias ações.

Filosofia, conhecimento, educação, cultura, ciência, na medida em que são atividades humanas, nascem, pertencem e movem-se necessariamente no âmbito concreto de uma existência social e historicamente determinada; por isso, devem ser interrogadas em seu ser com base não em critérios abstratos, mas por sua 
capacidade concreta de problematização ou de mistificação, de reprodução ou de transformação, de crítica efetivamente penetrante ou de mera legitimação $e$ "racionalização" da vida (social) e do mundo (histórico) em que existem e se constituem concretamente.

2. O problema da verdade, do conhecimento e do saber não se coloca, primariamente, em termos de uma questão pela adequação entre o enunciado e o real, ou pelas condições internas, epistemológicas e discursivas, de formação, funcionamento e validação de seus enunciados. Como atividade situada, concreta e determinada de homens e mulheres reais, a produção de conhecimento não nasce de si mesma, não explica-se a si mesma, nem esgota-se em si mesma; na medida em que não é a consciência que determina a vida, mas a vida que determina a consciência, na produção de conhecimento o que antes de tudo se põe em jogo é o problema crucial das condições, determinações e premissas extradiscursivas desde as quais delineia-se a hegemonia histórico-social de um determinado regime de produção, seleção, sistematização, normalização, homogeneização, circulação, distribuição, validação e legitimação dos enunciados e de sua enunciabilidade.

O que antes de tudo importa, portanto, é o modo como o conhecimento, ou como um regime de produção de conhecimento, ao delimitar seu objeto e sua problemática, produz na mesma medida suas próprias premissas, condições, regimes e efeitos de verdade e poder. Como produção humana, como atividade poética em que a vida produz-se a si mesma na mesma medida em que gera sua inteligilidade, seu "mundo", sua própria compreensão de si e o sentido de sua própria relação consigo mesma e com tudo que a cerca, o pensamento, ao constituir-se como expressão de uma experiência vital, constitui na mesma medida uma determinada subjetividade e uma determinada objetividade, uma determinada sensibilidade e um determinado horizonte de enunciabilidade, compreensibilidade, cognoscibilidade e comunicabilidade do mundo e da própria experiência de ser _cuja gênese, cujos limites e cuja existência concreta permanecem inexplicáveis enquanto não formos capazes de pensar as forças extradiscursivas que as determinam.

Já a própria multiplicidade concreta de determinações dos enunciados, discursos e teorias indica a existência extra-discursiva de diferentes situações, posições e interesses históricos concretos, que evidenciam o que Althusser pensou como o "caráter tópico do pensamento" _ ou seja, o modo como um pensamento produz e concebe seu próprio objeto, sua própria linguagem, sua própria problemática, sua própria referência.

Afinal, como diz Marx, não é possível pensar a produção de conhecimento em termos de uma autonomia das idéias e de sua produção em relação à historicidade dos modos de produção da vida pela própria vida e às experiências, práticas, relações e interesses que se formam e se desdobram concretamente em seu interior. 
São os seres humanos que produzem suas representações, suas idéias, etc., mas os seres humanos reais, atuantes, tais como eles são condicionados por um determinado desenvolvimento de suas forças produtivas e das relações que a elas correspondem, inclusive as mais amplas formas que estas podem tomar. A consciência nunca pode ser mais do que o ser consciente; e o ser dos seres humanos é o seu processo de vida real (...) A moral, a religião, a metafísica e todo o restante da ideologia, bem como as formas de consciência a elas correspondentes, perdem logo toda a aparência de autonomia. Não tem história, não tem desenvolvimento; ao contrário, são os seres humanos que, desenvolvendo sua produção material e suas relações materiais, transformam, com a realidade que lhes é própria, seu pensamento e também os produtos de seu pensamento. Não é a consciência que determina a vida, mas sim a vida que determina a consciência. [2] (p.20)

3. A pergunta que antes de tudo deve se dirigir a todo pensamento e a toda produção de conhecimento e consciência adquire então o tom do questionamento que Nietzsche e Marx, cada um a seu modo, vão dirigir ao pensamento: que espécie de práxis, que espécie de relação com a própria vida, que tipo de concepção da vida e do mundo organiza os pressupostos e dirige o devir e a criatividade de uma obra de pensamento ? Qual seu instinto, sua pulsão, seu afeto, seu interesse predominante, e como ele é capaz de organizar a partir e em torno de si toda a produção intelectual ? Que condição e situação, que posição e que interesses e valores concretamente históricos aí se afirmam e se tornam criadores? Que práxis aí se afirma, se expressa e secreta sua consciência de si, seu discurso, suas racionalizações? Que espécie de coações estruturais confere aos pensamentos seus limites, como limites da cognoscibilidade e da enunciabilidade do mundo no âmbito de uma obra de pensamento, como limites extra-discursivos que nunca ultrapassamos na vida, fixados por nossa própria condição, formação, posição $e$ interesse de classe no sistema de relações de poder e dominação, como diria Marx _ ou pela própria constituição afetiva, pulsional e fisiológica de nossos corpos, pela intensidade e qualidade de nossa vontade, de nossa potência, de nossa atividade vital, como diria Nietzsche?

Em que medida nosso pensamento já não se acharia sempre condicionado, bloqueado por certas barreiras e limites constitutivos da própria sociedade, e não da mente, dos quais só poderia desfazer-se pela transformação da própria sociedade, de nossa posição nela, ou de nossa relação com ela?

Essas barreiras não são apenas ideológicas; já desde Gramsci dá-se a transição crucial da concepção de ideologia como mero "sistema de idéias" para sua concepção como prática efetivamente internalizada, que abrange em si dimensões inconscientes, imaginárias, não explicitadas e não articuladas da própria experiência existencial, social e gnoseológica dos sujeitos, que se constituem, se materializam e se expressam, a cada hora e a cada dia, nos rituais, aparelhos, instituições, hábitos, costumes e valores que conformam a vida cotidiana. Como o que se expressa e se materializa no funcionamento das instituições, das unidades de produção, das práticas disciplinares e dos diversos dispositivos e técnicas de controle social que atuam na formação e na sujeição dos sujeitos_[3], a ideologia 
não é um fenômeno propriamente "ideológico": ela existe nas práticas e relações sociais em que se materializa e no modo como elas são efetivamente capazes de constituir, sujeitar e socializar os sujeitos em sua cotidianidade. Como concepção de mundo, ela é a expressão ideal e muitas vezes idealizada das práticas e relações sociais que materializam e expressam as relações de força, poder e dominação que estruturam uma determinada formação social.

É nesse sentido que deveríamos poder reconhecer que o que propriamente configura um regime epistêmico, sua problemática e seus limites constitutivos não são equívocos ou lapsos de comunicação, mal-entendidos da linguagem ou mesmo mecanismos de bloqueio epistemológico internos às próprias formações discursivas; são antes de tudo forças extra-discursivas que, mais ou menos sutilmente, demarcam a gênese, a emergência, o vigor, os limites, a efetividade e a ressonância dos discursos, das formações discursivas e do regime de sua produção. Mas não se trata aí simplesmente de reconhecer que, no interior da própria problemática, os discursos acabam, pelas mais diversas vias, tornando-se meios de reprodução, sanção, legitimação e racionalização de uma ordem social fundada em relações de força, poder e dominação; o que de fato é infinitamente mais difícil de captar são os mecanismos pelos quais a dominação da linguagem, do sentido e do próprio pensamento inscreve-se em nossa própria fala, em nossa própria escuta, em nossa própria comunicação.

É o que Habermas tem em mente quando nos diz que uma estrutura de linguagem, comunicação e pensamento sistematicamente distorcida é capaz de produzir, sem mais, uma aparência de normalidade e racionalidade. Distorção que na visão de Habermas remete à presença oculta ou latente de forças extra-discursivas no interior da comunicação, forças que presentificam-se por sua capacidade concreta de reproduzir silenciosamente, no interior do discurso, como suas próprias premissas, as mesmas premissas que atuam na produção e reprodução de uma sociedade constituída por relações de força, poder e dominação. Assim como "os pensamentos das classes dominantes tendem a se afirmar, em todas as épocas, como os pensamentos dominantes", no interior de uma ordem social fundada em relações de força, poder e dominação essas relações tendem a constituir, direta e/ou indiretamente, as premissas silenciadas e não-problematizadas a partir e em torno das quais se determina a vigência de toda uma estrutura hegemônica de linguagem, comunicação e pensamento; sem serem explicitadas ou problematizadas, elas determinam o horizonte da comunicação, que se desdobra como rede, como circuito de enunciados e racionalizações que se funda $e$ se desdobra a partir de premissas extra-discursivas que, uma vez tomadas como evidentes, tornam-se constitutivas dos objetos, da linguagem, dos significados e dos próprios sujeitos do discurso. Uma rede de comunicação deturpada, vai nos dizer Habermas, tende a ocultar e mesmo a erradicar a possibilidade de perceber as normas pelas quais se poderia julgar que ela está sendo deturpada, tornando assim impossível que, de dentro da própria rede, se possa levantar a questão pelas premissas normativas que a constituem. As condições históricas de possibilidade do sistema acabam assim sendo redefinidas pelo próprio sistema, terminando por desaparecer dentro dele, de modo que se torne impossível pensar, indagar, significar ou desejar algo que se ache fora das premissas do próprio sistema. 
4. É nesse sentido que faz-se necessário interrogar o pensamento em função de sua capacidade de mascarar ou desmascarar, em suas próprias premissas, as relações de força, poder e dominação que regem, condicionam, organizam e atravessam toda uma formação social. Trata-se de saber se o pensamento, se a produção de conhecimento assume como sua tarefa pensar, em toda sua radicalidade, o modo como essas relações de força organizam, se materializam e se expressam, em todos os fenômenos da vida social, como sua condição e seu próprio fundamento _ ou se, pelo contrário, ele tende a mascarar, pelas mais diversas vias, as relações de força que organizam a sociedade e o Estado de classes, assumindo-as como premissas não-problematizadas e sequer problematizáveis de suas racionalizações, e fazendo, assim, de suas próprias racionalizações a expressão ideal e idealizada, alienada e alienante das relações de força, poder e dominação que constituem $e$ organizam, em todos os níveis e sentidos, um determinado modo de produção da vida pela própria vida.

Essa é a questão crucial, que antes de tudo devemos saber dirigir a todo pensamento e a todo enunciado: trata-se de saber se concebemos e efetivamente assumimos o pensamento como trabalho de crítica e desconstrução sistemática, minuciosa e implacável das premissas e mecanismos estruturais do regime sociometabólico do capital, de sua produtividade ontológica, gnoseológica, social, cultural e subjetiva, de seu processo civilizatório e de seu regime epistêmico, ideológico e cultural _ou se, pelo contrário, acabamos, muitas vezes involuntária e inconscientemente, por assumir e internalizar essas premissas, suas práticas, conceitos, regimes e procedimentos, como se fossem necessárias, eternas e universais, tomando-as como o que constitui o regime não-problematizado $e$ sequer problematizável em que se fundam os enunciados e racionalizações tidas como possíveis e colaborando, assim, para sua normalização, legitimação e racionalização como condições supostamente estruturantes de toda realidade, de toda sociabilidade e de todo conhecimento possível.

Decerto que esse modo de colocar a questão desafia abertamente o pressuposto tácito de que o regime sócio-metabólico (cf. István Mészáros) do capital seria, para nos valermos da caracterização de Hegel, "eterno, necessário, permanente e universal" [4]_o que, uma vez aceito, como costuma sê-lo no regime hegemônico, torna supérflua qualquer discussão séria em torno do modo como a lógica, a gnoseologia, a subjetividade e a sociabilidade inerentes ao regime socio-metabólico do capital inscrevem-se na raiz dos processos históricos, sociais, culturais, epistemológicos e comportamentais modernos e contemporâneos. Uma vez aceita a insuperabilidade histórica e o caráter inelutável da relação capital, do modo de produção de subjetividade e sociabilidade e do mundo histórico-socialmente constituído à sua imagem e semelhança como ponto de partida do regime hegemônico de produção intelectual, torna-se implícita a pressuposição de que teríamos chegado ao "fim da história" _ o que responde pela tendência dominante no sentido de "naturalizar" premissas, valores, comportamentos, conceitos e linguagens estruturantes do processo civilizatório moderno e contemporâneo, como se elas derivassem diretamente de uma suposta natureza humana, ou senão, de 
um processo cultural cujas premissas e raízes talvez pudessem nos falar de algo assim como uma natureza humana.

Nesse contexto, torna-se igualmente implícito em que sentido o regime de produção intelectual hegemônico (na medida em que ele parte do pressuposto de que as condições e determinações gerais da existência e do próprio mundo sob o regime do capital tornam-se condições e determinações gerais do mundo e da própria existência em geral) pertence ele mesmo ao metabolismo social do regime do capital_seja como seu instrumento, insumo imaterial e força produtiva, como produtor de sua cognoscibilidade, de sua discursividade, de sua cultura e de suas condições de legitimação ideológica, como dimensão constituinte do processo de produção de subjetividades e consciências "adequadas" a sua própria ordem de dominação social, como sua racionalização necessária, sua mistificação, sua justificação, ou até mesmo como sua própria apologia ideológica.

Todas essas considerações nos colocam a questão decisiva pelas práticas, atitudes, procedimentos, relações, hábitos, normas e conceitos mediante os quais a produção de conhecimento se configura, no interior do regime socio-metabólico do capital e de toda sua produtividade ontológica, histórica, social, ética, cultural, gnoseológica e subjetiva, como seu reflexo, sua racionalização, sua produção de consciência _ gerando, na mesma medida, uma multiplicidade de saberes $e$ enunciados que lhe pertencem, em suas trocas recíprocas no interior do mesmo regime hegemônico de produção de conhecimento, como saberes e enunciados que, nos mais diversos sentidos, lhe são próprios, necessários e/ou adequados do ponto de vista da produção e da reprodução, da internalização e da legitimação de sua realidade histórico-social, de seus pressupostos cognitivos e ideológicos, de suas condições operativas e de suas próprias premissas estruturais.

Dada a abrangência da questão colocada à guisa de introdução a nosso problema, nos concentraremos nesse artigo apenas na questão pelas coerções estruturais, pelos regimes epistêmicos e pedagógicos e pelos dispositivos disciplinares que constituem, de início e na maior parte das vezes, a institucionalização e a sistematização da produção e do ensino de filosofia no interior do regime sociometabólico do capital [5].

Do ponto de vista de sua institucionalização e sistematização no interior do aparelho universitário, a produção e o ensino de filosofia se configuram, de início e na maior parte das vezes, a partir de um conjunto de procedimentos, práticas, operações e dispositivos disciplinares que incidem decisivamente sobre a produção de conceitos e de sujeitos sociais da produção de conhecimento; em sua articulação recíproca, eles determinam, com todo o seu peso normativo, a disciplinarização, normalização, homogeneização e canonização da atividade filosófica, delineando as condições de sua regularidade e de seu funcionamento.

Em sua materialidade própria, esse conjunto de práticas, dispositivos e procedimentos se expressam numa série de "primados", que em sua articulação 
recíproca operam no sentido de determinar a atividade filosófica do ponto de vista de sua constituição, de sua normatividade e da regularidade sistemática de seu funcionamento como razão disciplinar. Nos efeitos de verdade e poder gerados pela eficácia prática, normativa e disciplinar desse enquadramento, vivemos o que poderíamos designar como a domesticação da filosofia; no tipo de sistematização, normalização e padronização que daí resulta, se nos coloca o desafio de pensar a série de procedimentos que, ao longo dos tempos, tem institucionalizado, regularizado e sistematizado o ensino e a produção da filosofia do ponto de vista do que poderíamos designar como o domínio de uma razão e de uma racionalidade imperial.

\section{Da Série de Primados e Dispositivos da Razão Disciplinar}

\section{O Primado da Verdade sobre o Ato/Atividade (Do Controle Disciplinar do Pensamento)}

Do ponto de vista da razão disciplinar, de seus procedimentos e normas tácitas, de suas exigências e personificações, o ato/atividade de pensar deve ser regulado, disciplinado e controlado no interior de uma referência prévia à verdade, ou a uma determinada ordem ou regime de produção da verdade que, emanando da autoridade de um texto, de uma obra, de um autor, de uma escola, de um canône ou de uma tradição qualquer de pensamento, antepõe-se ao ato/atividade de pensar como medida de sua verdade ou falsidade e como sua própria condição de possibilidade, legitimidade e validade.

Antepõe-se assim à singularidade e à concretude do ato/atividade mesma de pensar a categoria filosófica da verdade _ verdade reificada e reificante, fetichizada e fetichizante, que produz seus próprios efeitos de verdade, poder e dominação precisamente na medida em que conforma uma rede de enunciados, uma ordem do discurso e toda uma lógica da enunciação capaz de definir, de antemão e de acordo com seus próprios termos e premissas, os parâmetros e condições de possibilidade de toda enunciação possível.

A subordinação da enunciação, como ato/atividade de pensamento, à ordem reificada e reificante de um sistema, ou de uma rede de enunciados que define de antemão a medida e as possibilidades da enunciação e da enunciabilidade: eis aí o dispositivo, anti-filosófico por excelência, pelo qual se conforma, se domestica e se enquadra o pensamento no interior das premissas não-problematizadas e sequer problematizáveis de uma determinada ordem, ou regime epistêmico de produção da verdade que é também um regime de produção da referência e da referencialidade, da identidade e da diferença, da verificabilidade e da validadade, da enunciação e da própria enunciabilidade, no interior do qual se redefinem as premissas e condições de possibilidade de todo o sistema, de modo que acaba por tornar-se impossível pensar, significar, indagar ou propor algo que se ache fora das premissas auto-referenciadas do próprio sistema.

As condições de possibilidade do pensamento tendem desse modo a coincidir com as condições de possibilidade de uma determinada ordem, regime ou sistema de 
pensamento; mediante essa identificação/redução do pensamento aos termos de uma determinada ordem do discurso, que define em seu interior a cognoscibilidade e a enunciabilidade do próprio real a ponto de pretender recobri-lo inteiramente, o pensamento busca assegurar-se de si mesmo e de sua verdade na mesma medida em que busca reduzir todos os fenômenos a sua própria imagem e semelhança; desse modo, ele tende a transformar a singularidade e a multiplicidade dos fenômenos num mero simulacro, ou a expulsá-las para fora de suas fronteiras, na mesma medida em que reafirma tautologicamente sua própria certeza de si. Sua problemática tende assim a se articular em torno de certos pressupostos, silêncios e elisões eloqüentes, sendo construída de tal modo que as questões que podem ser formuladas dentro dela já induzem a certos tipos de resposta. O que desse modo tende a se formar é uma espécie de aparelhamento do pensamento, muitas vezes confundido com seu rigor e sistematicidade; nesse aparelhamento, o pensamento tende a fechar-se sobre si, no interior de uma estrutura circular, auto-fágica e autoconfirmadora, em que para onde quer que nos movamos somos sempre remetidos ao que se supõe como seguramente conhecido.

A necessária identificação, consciência e problematização das condições, forças e interesses extra-discursivos que formam as premissas constituintes, as perspectivas e os próprios limites de uma obra, de uma ordem ou de um regime de pensamento e produção de conhecimento, bem como seus efeitos de verdade e poder, tende assim a desaparecer em nome do predomínio de uma série de práticas e procedimentos de natureza intra-discursiva, que se dobram e se redobram indefinidamente sobre si mesmos.

O controle do pensamento se estabelece assim como controle sobre as condições de produção, legitimação e validação dos enunciados do pensamento _ que se torna tanto mais poderoso e eficaz quanto mais for capaz de fazer desaparecer, em seu próprio interior, a possibilidade fundamental de se colocar em questão os pressupostos e as condições extra-discursivas de sua própria formação.

Em outros tempos, como observa Foucault [6], o controle na produção dos enunciados era obtido por meio de uma vigilância rigorosa sobre a ortodoxia dos enunciados; mas a ortodoxia, como modo de controle externo do saber, de sua produção, de seu ensino e de sua sistematização por um aparelho religioso, eclesiástico, era bastante onerosa, na medida em que acarretava na condenação e exclusão de enunciados cientificamente verdadeiros e fecundos; em todo caso, ela era incompatível com o modo de produção que se afirmava, que a condenaria como obsoleta, não em nome de uma emancipação do pensamento, mas para propor formas de controle mais adequadas à racionalidade do novo modo de produção.

Em nossos tempos, de acordo com as premissas, condições, demandas e exigências do novo modo de produção, o controle dogmático do saber pelos mecanismos da ortodoxia foi substituído por outra forma de controle, que não incide propriamente sobre o conteúdo dos enunciados, sobre sua conformidade ou 
não com certa verdade pressuposta, mas, como diz Foucault, sobre o regime epistêmico de produção e validação dos enunciados, sobre a regularidade dos enunciados e da enunciação, mediante um aparelho a isso destinado, o aparelho universitário.

Introduz-se assim uma forma de controle que passa a incidir sobre a disciplina interna dos saberes, sobre sua constituição e sobre os mecanismos subjacentes à sua produção e a seu ensino. Nas palavras de Foucault:

O problema será saber quem falou e se era qualificado para falar, em que nível se situa esse enunciado, em que conjunto se pode colocá-lo, em que e em que medida ele é conforme a outras formas e tipologias de saber. Isso permite ao mesmo tempo, de um lado, um liberalismo num sentido, senão indefinido, pelo muito mais amplo quanto ao próprio conteúdo dos enunciados e, do outro, um controle infinitamente mais rigoroso, mais abrangente, mais amplo em sua superfície de apoio, no nível mesmo dos procedimentos da enunciação. $\mathrm{E}$, com isso, deduz-se daí naturalmente uma possibilidade de rotação muito maior dos enunciados, um desgaste muito mais rápido das verdades; daí um desbloqueio epistemológico. Assim como a ortodoxia incidente sobre o conteúdo dos enunciados pôde ser um obstáculo à renovação do estoque dos saberes científicos, assim também, em compensação, o disciplinamento ao nível das enunciações permitiu uma velocidade de renovação dos enunciados muito maior. Passou-se, se vocês preferirem, da censura dos enunciados para a disciplina da enunciação, ou ainda da ortodoxia para algo a que eu chamaria a "ortologia", que é a forma de controle que se exerce agora a partir da disciplina. [7]

Ainda sobre as condições epistêmicas de produção da verdade, Foucault nos diz, em outro momento:

Produzida por "um conjunto de procedimentos regulados para a produção, a lei, a repartição, a circulação e o funcionamento dos enunciados"(...), "a verdade está circularmente ligada a sistemas de poder que a produzem e a apoiam, e a efeitos de poder que ela induz e que a reproduzem. 'Regime' da verdade. Esse regime não é simplesmente ideológico ou superestrutural; foi uma condição de formação $e$ desenvolvimento do capitalismo. É ele que, com algumas modificações, funciona na maior parte dos países socialistas (...)".

[Nesse sentido], "o problema político essencial para o intelectual não é criticar os conteúdos ideológicos que estariam ligados à ciência ou fazer com que sua prática científica seja acompanhada por uma ideologia justa; mas saber se é possível constituir uma nova política da verdade. O problema não é mudar a consciência das pessoas, ou o que elas tem na cabeça, mas o regime político, econômico, institucional de produção da verdade.

Não se trata de libertar a verdade de todo o sistema de poder _ o que seria quimérico na medida em que a própria verdade é poder _ mas de desvincular o poder da verdade das formas de hegemonia (sociais, econômicas, culturais) no interior das quais ele funciona no momento. 
Em suma, a questão política não é o erro, a ilusão, a consciência alienada ou a ideologia; é a própria verdade. [8]

O problema da verdade como o problema da sua produção, ou mais precisamente, como o problema da colonização das condições e do regime de sua produção; a verdade, portanto, como problema essencialmente político, que diz respeito à própria produção da consciência e, consequentemente, à formação das práticas e dos conceitos pelos quais se formam, se reconhecem, se comunicam e se interpelam entre si os próprios sujeitos sociais. Não se trata, portanto, de entender o problema político como o problema do erro, da ilusão, da consciência alienada, ou dos efeitos ideológicos de um determinado regime social de dominação: o que produz o consentimento a um regime de dominação, a uma sociedade e a um Estado de classes (e na mesma medida produz e reproduz as práticas, os sujeitos, as relações e os conceitos adequados à sua reprodução), é antes de tudo a vigência de um regime de produção da verdade e da consciência, da cognoscibilidade e da comunicação, que se inscreve e se afirma, em sua "verdade" e em seus efeitos de verdade e poder, como a expressão ideal das relações materiais de dominação que atravessam e organizam toda a formação social. Seus efeitos de verdade vêm precisamente de que ela expressa, na ordem do discurso, a "verdade" de uma certa ordem de produção e reprodução da dominação; em outras palavras, o que ela expressa é a "verdade" que se impõe como adequada e plausível à consciência dos próprios sujeitos sociais que se constituem, se socializam e têm de existir, se adaptar e se inserir no interior da ordem social de dominação em que vivem.

A emergência histórica de uma outra política da verdade decerto exigiria "desvincular o poder da verdade das formas de hegemonia no interior das quais funciona ele funciona no momento"; o que não pode implicar que devamos esperar o advento dessa desvinculação como quem espera por um milagre ou pela salvação _ou mesmo como quem espera pelo dia da revolução como dia da libertação; para que esse dia chegue, devemos saber prepará-lo, agindo no próprio interior da política da verdade sob a qual vivemos hoje.

Esse trabalho exige que se aprenda a inverter o primado da verdade sobre o ato, sobre a atividade de pensar. Uma inversão subversiva; através da qual se restitui à liberdade, à potência e à criatividade do pensamento o seu primado sobre a verdade e sobre as ordens e regimes de produção e reprodução da verdade que tem trabalhado sistematicamente pela domesticação, pelo enquadramento e pela colonização do pensamento; inversão que se realiza apenas na medida em que se assume a questão pelas premissas constituintes de uma ordem social de dominação como questão que indaga, ao mesmo tempo, pelas premissas da racionalidade $e$ da discursividade que produz, expressa e reflete, a seu modo, a ordem de dominação de que ela é a expressão ideal; inversão essencialmente transgressora, na medida em que assume como sua liberdade, sua atividade e sua própria necessidade desmascarar as relações de força, poder e dominação que constituem, silenciosamente, as premissas, a problemática e o sentido de todos os discursos, de todos os conceitos e da própria rede de comunicação em que se articula a racionalidade imanente à produção, normalização e reprodução da ordem social de dominação, sua hegemonia e sua pretensão à universalidade e à naturalidade. 
São muitas as coerções estruturais que operam na produção da "verdade", nos modos e procedimentos de sua reificação e na própria formação de um regime hegemônico de produção, circulação, legitimação e validação da "verdade" _ e não é senão por isso que a necessária liberação da possibilidade de pensar só pode mesmo partir da identificação dos modos pelos quais essas múltiplas coerções se tornam propriamente produtivas na mesma medida em que se tornam invisíveis para si mesmas.

Não é a atividade de pensar que deve se submeter à reificação de seus próprios produtos, alienando-se neles e, nessa alienação, renunciando a si própria em nome de sua certeza de si; pelo contrário, é a própria atividade de pensamento que, no vigor de sua potência criativa, produz a verdade como um momento determinado de sua própria auto-realização. Em verdade, a inversão aqui postulada apenas restitui ao pensamento o direito a sua própria dignidade, a sua própria potência, a sua própria liberdade, como condição de possibilidade do próprio pensamento; reconhecer o primado ontológico e epistemológico da atividade pela qual se produz a verdade sobre a reificação da verdade assim produzida é, no fim das contas, reconhecer a necessidade do que em última análise se impõe pela própria atividade, pela própria liberdade, pelo vigor do próprio exercício do pensamento.

Mas para que as questões colocadas por esse "primado" possam ser aprofundadas de modo adequado, é necessário passar à enunciação $e$ análise dos outros primados, cuja articulação recíproca produz a totalidade concreta do processo pelo qual a razão disciplinar opera, no interior do aparelho universitário (e do próprio aparelho escolar como um todo), a partir da regularidade de suas próprias práticas e procedimentos, a reificação, a alienação e a colonização sistemáticas do pensamento e do conhecimento, da educação, da verdade e de sua própria produção.

\section{O Primado da Resposta sobre a Questão}

$\mathrm{Na}$ ordem da produção filosófica e da criação de conceitos, deveríamos ser capazes de reconhecer o primado das perguntas/questões sobre as respostas/soluções.

Na medida mesma em que uma problemática filosófica/científica caracteriza-se por ser aberta, ela pode ser transformada à medida que, em seu desenvolvimento, ela tende a gerar novos objetos, novos fenômenos, novas possibilidades de interpretação e interlocução _ e neles e por eles, novos horizontes de problemas e novos campos de questionamento, efetivamente capazes de abrir setores ou dimensões do real até então invisíveis, inacessíveis e/ou inexplorados.

Em sua démarche criadora, toda investigação avança na medida mesma em que cada resposta, ou cada resultado provisório que nela é obtido, em sua problematização, passa a gerar novos campos de questões e novos desafios de pensamento. 
O primado das perguntas sobre as respostas se afirma pelo fato de que cada resposta gerada, como resultado provisório, não só nasce de uma questão como abre, por sua vez, novos campos de questões, e com isso, novas respostas, das quais surgem novas questões, e assim indefinidamente.

O reconhecimento do caráter aberto, provisório, histórico e processual do real impõe à produção de conhecimento sua necessária abertura, processualidade, provisoriedade $e$ historicidade como condição mesma de sua atividade e fecundidade; é nessa abertura e por essa abertura mesma que se impõe o primado dialético do momento da pergunta sobre o momento da resposta no processo de produção do conhecimento, como primado ao mesmo tempo ontológico e epistemológico .

Na ordem imperial da razão disciplinar esse primado tende a ser invertido: a resposta, a síntese, a ordem, sua explicação e seu sistema é que passa a delimitar, regular e controlar, desde seus próprios termos, numa espécie de circuito que se retro-alimenta de si mesmo, a produção das perguntas e seu horizonte; as próprias perguntas tendem a ser condicionadas e domesticadas pelas respostas, ou mais precisamente, pelo campo epistêmico de antemão fixado pela racionalidade imanente à própria ordem do discurso a ser problematizado. A necessária problematização do sistema/ordem de pensamento que constitui as condições de referência, representação, cognoscibilidade e enunciação do próprio real tende assim a ser neutralizada pela anteposição do próprio sistema, da própria ordem, como instância de delimitação e regulação disciplinar da atividade de pensar e da disposição para a pergunta e para a problematização.

Domesticação dos problemas, domesticação do texto e de suas leituras, domesticação das condições e das relações de interlocução e de seus sujeitos e objetos, tudo isso passa a imperar, no interior da sistematização de uma razão propriamente disciplinar, justamente ali onde a resistência, a transgressão, a liberdade, a autonomia e a abertura do questionamento e da problematização deveriam poder ser reconhecidos como a condição mesma de todo pensamento $e$ de toda criação.

O momento da resposta passa assim a prevalecer sobre o momento da pergunta e em seu paroxismo, chega até mesmo a anulá-lo. O momento da necessária certeza de si acaba por condicionar e aprisionar, desde suas próprias exigências, o momento fecundo de sua necessária auto-superação.

No registro da razão disciplinar a liberdade do questionamento tende a ceder lugar $e$ até mesmo a confundir-se inteiramente com o arbítrio e desenvoltura autoreferenciada dos (supostos) saberes e de suas certezas hispostasiadas. A auto-ilusão dogmática se torna auto-consciência, na mesma medida em que o diálogo tende a desaparecer inteiramente em meio à ficção auto-complacente, auto-confirmadora $e$ auto-fágica do monólogo; nesse quadro, a dialogia necessária ao conhecimento desaparece em nome da reificação de toda uma série de pressupostos, (supostos) saberes e certezas que, em seu aparente rigor e em sua aparente onisciência, acabam por formar uma série de monoculturas do pensamento _ monoculturas 
que, por sua vez, agem como conteúdos e instrumentos dos processos de disciplinarização, reificação, alienação e colonização do próprio pensamento.

A consciência se forma como território a ser colonizado por essas monoculturas; o primado das respostas sobre as perguntas transforma a experiência do conhecimento numa espécie de aquisição progressiva de uma série de técnicas, procedimentos e habilidades no manuseio operacional adequado de verdades reificadas; o pensamento tende a se configurar assim como técnica de pensar, na mesma medida em que o ensino e o aprendizado tendem a se configurar sob a perspectiva reificante, alienanate, colonizatória e escravizante da mera transmissão de conteúdos e conhecimentos reificados.

\section{O Primado da Síntese sobre a Contradição e da Unidade sobre a Multiplicidade}

Na ordem da produção filosófica, deveríamos reconhecer na historicidade dialética do real o que impõe o primado ontológico e epistemológico dos antagonismos e contradições, das diferenças e oposições sobre toda espécie de empreendimentos que visam a sua síntese, reconciliação, encobrimento, neutralização ou esvaziamento.

Antagonismos e contradições, bem como toda a multiplicidade de forças, posições, interesses e perspectivas que neles se manifestam, são expressões da historicidade dialética do próprio devir.

Não obstante, no domínio auto-referenciado da razão disciplinar e de suas operações o domínio da síntese tende a se impor e se confundir com o domínio geral do pensamento, na medida em que os antagonismos e contradições inerentes à abertura, à historicidade $e$ ao devir do real tendem a ser devidamente reconciliados no interior do ponto de vista transcendental que produz a síntese como a sua própria síntese. Em seu interior, tudo se passa como se a multiplicidade, o antagonismo e a contradição das forças que atuam, se materializam e se evidenciam no devir pertencessem a uma unidade primordial prévia, ou a ela se dirigissem teleologicamente; ou como se a multiplicidade de posições, interesses e perspectivas representasse apenas um momento a ser superado e reconciliado na unidade superior do conceito e na verdade suprema da razão. O que assim se forma e passa a operar, como pressuposto do pensamento $e$ como condição (pressuposta) de sua possibilidade, é o que poderíamos designar como o ponto de vista da unidade (e da síntese) transcendental: responsável pela síntese do múltiplo e do diverso, ele representa o momento da síntese e da unificação como momento do comando, da ordem e da unidade, que deve se impor sobre a materialidade das múltiplas forças e posições que se embatem no devir do real e produzir sua reconciliação na unidade abstrata, transcendental e auto-referenciada do conceito e de sua ordem, de seu ordenamento e de sua ordenabilidade.

Nesse registro, a identidade deve se impor à alteridade, à diferença e à diversidade; o momento do comando (que se expressa seja como o momento da alma, da idéia, da razão, etc,.), sobre a materialidade do que deve poder ser comandado $e$ 
ordenado (momento do corpo, da matéria, do devir, etc,.); a ordem, sobre o que se destina a ser ordenado, e assim por diante _ como se na lógica do sentido que assim se expressa não houvesse nenhuma espécie de projeção inconsciente e involuntária do plano político sobre o plano ontológico e epistemológico _ou como se a historicidade de um determinado modo de produção da vida, de uma determinada ordem política da vida social, ou de um determinado modo de produção e reprodução das relações sociais como relações de poder e dominação não fosse ela mesma subjacente à lógica do sentido que desse modo se projeta do plano propriamente político em direção aos planos ontológico e epistemológico.

O primado das contradições sobre sua síntese e reconciliação transcendental, em sua evidência factual, precede ontologicamente a sua inversão no interior de uma racionalidade que exige essa inversão como condição de sua própria possibilidade; nesse sentido, se nos impõe a questão pelas condições extra-discursivas da síntese, e pelas próprias forças extra-discursivas que exigem, produzem, articulam e postulam a racionalidade da síntese como a própria racionalidade em geral.

O primado das contradições sobre sua síntese e reconciliação transcendental é antes de tudo uma determinação dialética da historicidade do próprio real, que em última análise responde por seu próprio devir, por sua própria abertura, por sua própria indeterminação constitutiva. $\mathrm{O}$ momento da síntese, no plano de imanência e consistência do próprio real e da correlação de forças que o constitui, equivale ao momento provisório em que uma de suas forças determinadas foi capaz de prevalecer; em sua historicidade dialética, a síntese é um momento determinado e constitutivo do devir (e não sua finalidade teleologicamente determinada), cuja própria existência pressupõe e depende ela mesma da existência prévia e constitutiva do múltiplo, de suas contradições e de toda a dialética de suas determinações e superações (aufhebungen) possíveis.

Quando o pensamento articula o ponto de vista transcendental de sua própria síntese, ele expressa e organiza o ponto de vista e a racionalidade de uma práxis determinada e o tipo de síntese que ela é capaz de constituir desde seu próprio ponto de vista _ e é a partir do retorno/repetição dessa mesma operação no interior de uma ordem social de dominação que vai se formando o hábito, a norma, a aparência e os pressupostos que configuram, a sua própria imagem e semelhança, uma lógica do sentido e toda uma noologia do pensamento. Sua síntese transcendental, reconciliadora, explicativa e conclusiva tende a absorver e a internalizar pelas mais diversas vias o que é outro e heterogêneo em relação a seu ponto de vista transcendental: seja reduzindo-o violentamente a sua própria imagem e semelhança, seja buscando explicar, desde seus próprios termos, sua origem e sua existência como erro, ilusão ou aparência.

Nessa operação, uma práxis determinada busca afirmar sua racionalidade como a própria racionalidade, na mesma medida em que busca constituir o mundo como o seu mundo.

O que assim se manifesta não é uma determinação interna ao pensamento: no interior de uma formação social marcada pelo antagonismo e pela contradição, o 
"primado da síntese transcendental", sua operatividade, sua normatividade, suas funções gnoseológicas e seus efeitos de verdade e poder (marca dos pensamentos dominantes que buscam articular-se como "expressões ideais das relações materiais dominantes"), apenas traduz o modo de ser e a gnoseologia de toda uma ordem, de toda uma produção de pensamento marcada pela luta em torno da hegemonia - luta que, por sua vez, constitui a materialidade do devir e do pensamento no interior de uma sociedade e de um Estado de classes e de todo um processo civilizatório cuja historicidade é a historicidade dialética de suas ordens e relações de poder e dominação e dos antagonismos, lutas, oposições e contradições que aí se manifestam.

Do ponto de vista de uma razão imperial e de uma racionalidade da dominação, nada disso pode ser explicitado ou pensado, na medida em que constitui a própria materialidade, a própria lógica, a própria operacionalidade do pensamento.

De um ponto de vista que situa-se, ou quer situar-se para além dessa racionalidade, o que se impõe como sua tarefa fundamental é a genealogia dos antagonismos e contradições e de toda a multiplicidade de forças que aí se embatem no devir do próprio real, da dialética de suas relações recíprocas e de suas formas de consciência _ o que por sua vez exige, na mesma medida, a produção $e$ a ativação de saberes que manifestem esses antagonismos $e$ contradições e sejam capazes de articular suas lutas e expressar as formas de consciência que dela nascem _ assim como a necessária desconstrução das práticas, dos conceitos, da racionalidade e da própria lógica do pensamento que se constituem sob a perspectiva de uma síntese transcendental.

\section{O Primado da Ordem/Lei sobre o Ordenado/Legislado}

O primado do poder sobre a potência, do poder instituído sobre o poder instituinte, ou do poderes constituídos sobre o poder constituinte funda, sustenta $e$ reflete a materialidade própria de toda ordem social de dominação _ do mesmo modo que, no âmbito da atividade de pensamento, o primado do poder sobre a potência, do constituído sobre o constituinte, expressa, em última análise, a lógica de toda uma ordem de pensamento que se destina a expressar-se como consciência adequada à vigência das relações de poder e dominação, de que ela mesma é sua expressão ideal.

A lei e sua ordem, bem como as estruturas de comando e seu modo de exercício, circulação, distribuição e aplicação do poder imperam sobre os corpos, sobre suas relações, suas trocas e seus lugares, sobre o espaço e as modos de sua espacialização, sobre o tempo e os modos de sua temporalização. No interior dessa ordem e do modo como nela se organizam os vínculos humanos, as relações sociais e a produção da vida pela própria vida em todos os seus aspectos e dimensões, o pensamento se manifesta, de início e na maior parte das vezes como expressão ideal, auto-consciência, reflexo ou instrumento da ordem social de dominação a que pertence, de que ele nasce e sobre a qual ele incide. Nesse sentido, ele tende a produzir seus conceitos como conceitos que pertencem a uma ordem de dominação como as próprias categorias em que se expressa idealmente 
a materialidade dessa dominação _ ou senão, de outro modo, qualitativamente heterogêneo e antagônico ao primeiro, ele tende a produzir seus conceitos como conceitos que servem à desconstrução e à transformação dessa mesma ordem, desencadeando um movimento em que as potências, forças e possibilidades recalcadas ou silenciadas no interior da ordem social de dominação irrompem na mesma medida em que liberam e impõem a possibilidade de pensar até o fim o que propriamente constitui essa ordem e questioná-la desde suas origens e premissas mais fundamentais.

No primeiro caso, o pensamento tende a refletir as premissas e as condições reais de existência no interior dessa ordem social como premissas e condições de toda existência em geral; ao assim fazê-lo, acaba por tomar o real como aquilo cuja realidade passa a coincidir com o modo de sua produção no interior das relações que o constituem. Toma-se assim a vida, a sociedade, a subjetividade, etc., como o que coincide com as condições específicas de sua constituição e de sua sujeição no interior de uma determinada ordem histórico-social_e é desse modo que o próprio pensamento acaba por fazer com que a compreensão da realidade constituída absorva em suas próprias determinações não só as condições de sua constituição, como o próprio poder constituinte que, em sua potência de existir, mostra-se sempre capaz de resistir, questionar, transgredir, implodir e superar a realidade constituída.

O primado da ordem sobre o que nela é ordenado é ao mesmo tempo o primado do poder sobre a potência, da lei sobre o que deve ser legislado, da reificação sobre o que é reificado _ que se expressa também como o primado do constituído sobre o constituinte, ou como o primado das condições objetivas da existência e do círculo de ferro de suas determinações sobre as potências subjetivas cuja atividade vital é capaz de criar outros modos de relação com essas condições objetivas, de gerar outros modos de considerá-las, de agir sobre elas, de subvertê-las e transformá-las.

Há sempre uma razão e uma racionalidade que servem ao poder, e cuja existência e soberania dependem precisamente do poder a que servem e de que elas são sua expressão ideal_assim como há sempre uma razão e uma racionalidade que expressam a liberação das potências ativas que se acham sujeitadas e disciplinadas sob determinados modos de produção, reprodução, circulação e distribuição do poder.

A primeira expressão da racionalidade expressa sempre o primado da ordem sobre o que é ordenado; ela é a razão da lei, e da naturalização da própria lei, que se constitui como razão na medida em que expressa a racionalidade da lei como sua própria racionalidade

A segunda se articula sempre a partir da inversão desse primado: a lei aparece aí não em sua própria reificação como lei, mas à luz da dialética que se estabelece entre a lei $e$ isso mesmo sobre o que ela pretende legislar, entre a ordem $e$ isso mesmo que ela pretende ordenar, dialética segundo a qual aprendemos a considerar a historicidade do real do ponto de vista de sua própria abertura, de sua 
própria indeterminação _ que é ao mesmo tempo o ponto de vista de sua própria auto-construção, de sua própria auto-superação e, portanto, da subjetividade em luta que aí se expressa como sua própria condição de possibilidade.

A lei aparece, dessa perspectiva, como a expressão provisória da historicidade aberta e dialética de uma certa correlação de forças e dos antagonismos que ela pretende controlar, encobrir, absorver ou neutralizar; em outras palavras, como poder, e não como potência, como expressão da objetividade e da objetivação, $e$ não da subjetividade e da subjetivação; como algo constituído, portanto, e não como realidade primária e transcendental.

Devemos aprender a romper a camisa-de-força que assim se impõe ao pensamento, aprendendo a inverter mais esse primado da razão disciplinar, afim de que as condições de uma ordem determinada possam aparecer como o que elas são: como condições relativas de uma ordem determinada, de seus mecanismos e agenciamentos de sujeição e constituição do real, dos processos de sua produção $e$ dos sujeitos de sua produção e reprodução social _ portanto, como condições que podem ser superadas, que devem ser superadas, e que em verdade começam a ser superadas demolição ali mesmo onde se ativam os saberes em luta que são capazes de engajar-se no trabalho subversivo de sua própria desconstrução, de sua própria.

\section{A Pedagogia da Razão Disciplinar [9]}

Se cada um tem de se pôr em seu lugar na hierarquia de uma ordem social estruturalmente desigualitária, considera-se "natural" que haja um lugar destinado especialmente àqueles que vão produzir os conceitos e as razões que expliquem, critiquem, justifiquem ou legitimem a vida e a sociedade _e um lugar destinado a todos os outros, ao resto portanto, que por suas condições de existência, por sua incapacidade relativa $e$ por seu lugar na ordem social e na divisão do trabalho se supõe que sejam desprovidos dos conhecimentos mínimos e incapazes de pensarem por si mesmos, ou ao menos de pensarem de acordo com o rigor dos padrões conceituais que vão julgar a correção, a validade, o mérito e a legitimidade destes pensamentos.

Dir-se-ia que "as coisas são assim" _ e que deveríamos agir de acordo com o seu "ser assim". Ou que a própria divisão do trabalho _ e notadamente a divisão entre o trabalho manual e intelectual_impõe que assim seja.

Supõe-se assim como "natural" que os camponeses cuidem da terra, e apenas dela, que os operários se ocupem da produção industrial, e apenas dela, que os economistas cuidem dos anseios e demandas do "mercado", e de nada mais _e que os "filósofos", ora, que os "filósofos" expliquem aos outros, ao resto portanto, o que eles são e o que é o mundo em que vivem, mesmo que os outros, que o resto, segundo asseveram os próprios "filósofos", não se ache em condições de compreender, e muito menos de avaliar a verdade das proposições de que eles mesmos e seu mundo são objetos. 
Deste modo, se divide o mundo em dois, como no mito original de toda pedagogia _ ou ao menos de toda pedagogia tradicional: de um lado, os que sabem, se supõe que sejam capazes de ensinar e na divisão hierárquica do trabalho social se ocupam de explicar aos outros o que é o mundo; de outro, o resto, os que não sabem, a quem não é dado saber e que se supõe que sejam incapazes de pensar e aprender qualquer coisa por si mesmos _e que portanto devem ser instruídos.

Há um abismo entre o empenho pela práxis e pela consciência ativa da relação recíproca e da dialogia necessária no trabalho em comum de investigação, descoberta e problematização da vida e do mundo em que vivemos (empenho em que os processos educacionais e cognitivos se concebem e se organizam tendo em vista a emancipação da atividade de pensamento dos sujeitos pelo trabalho comum de investigação e descoberta, de crítica, problematização e desconstrução de seu próprio mundo comum) _ e toda espécie de práticas, racionalizações e consciências que se formam ali onde se pressupõe, se "naturaliza", se reitera a crença na hierarquia das inteligências, na desigualdade das inteligências e das capacidades; crença pela qual o mundo é dividido em espíritos superiores e inferiores; crença que em última análise se limita a refletir, racionalizar e legitimar os pressupostos, fundamentos, preconceitos, desejos, ambições e relações de poder e dominação que reproduzem, em seus próprios termos, uma ordem social de dominação (o que já se constitui desde o início como procedimento pedagógicofilosófico ético-político e existencial em que assume-se, tacitamente, inconscientemente, dir-se-ia, "naturalmente", toda uma série de premissas que se impõem como as premissas dos próprios processos educacionais, formativos e cognitivos).

Para começar a transpor esse abismo, seria necessário (re)começar pela consideração do que propriamente se pretende quando se ensina algo a alguém questão ao mesmo tempo filosófica, existencial, ética, política e pedagógica, absolutamente decisiva para a filosofia e seu ensino, para a educação e para toda $e$ qualquer teoria ou filosofia da educação que não se resigne a confinar-se aos limites estreitos da consciência, da ideologia e dos tipos de racionalização que correspondem à internalização acrítica, ahistórica e anti-filosófica das próprias premissas estruturais que sustentam e legitimam a ordem social de dominação em que vivemos.

Afinal, o que de fato se pretende quando se ensina algo a alguém ? E o que de fato se supõe quando se pretende que seja possível ensinar algo a alguém?

De modo geral, nos acostumamos a acreditar que educar é ensinar algo a alguém. No quadro desta pressuposição, a tarefa do mestre é transmitir e explicar ordenadamente seus conhecimentos aos alunos, para elevá-los gradualmente à sua própria ciência, e assim formar os espíritos, levando-os, segundo uma progressão calculada na ordem das razões, do mais simples ao mais complexo, e deste modo, habilitando-os à apropriação, ao manejo e à utilização racional e adequada de todos os hábitos, procedimentos e saberes necessários à sua capacitação, inserção e reconhecimento social e profissional. $\mathrm{O}$ "aluno" (aquele que não dispõe de luz própria e a quem a luz deve ser transmitida por quem a possui) existe como aquele 
a ser formado; isto é, como aquele que deve tornar-se capaz de adquirir, manejar, internalizar e sujeitar-se adequadamente aos saberes, hábitos, normas, padrões, procedimentos e comportamentos requeridos para que possa vir a habilitar-se competitivamente à conquista de um lugar na ordem social (supondo tudo o que isso pressupõe (...), e que afinal todos nós conhecemos, pois já passamos por isso, cada um(a) a seu modo).

Supõe-se assim muitas coisas, que a rigor são as mesmas que se supõe quando se trata de levar a "filosofia" ao "senso comum", e as mesmas que, em última análise, fazem de toda educação ("tradicional") uma mera conformação, mais ou menos adequada e eficiente, dos pressupostos que refletem, organizam, operacionalizam, justificam e legitimam a ordem social que a sanciona.

Na verdade supõe-se aí tantas coisas que vou me deter em apenas uma, que talvez seja a mais fundamental dentre as suposições que costumamos fazer quando racionalizamos sobre problemas relativos ao ensino e à educação. .

Quando se supõe possível ensinar filosofia a alguém, pensa-se na filosofia como alguma coisa que existe antes de ser ensinada, e ao assumir esta suposição, que a princípio parece óbvia demais, pensa-se na filosofia como algo a ser ensinado por alguém competente, que detém este saber, a alguém que não o detém (na mesma medida em que supõe que a filosofia é uma disciplina distinta de todas as outras, com seus conteúdos e métodos específicos, e não uma atividade que perpassa, ou ao menos deveria perpassar, como seu elemento próprio, a criação e a produção de conceitos, bem como todos os processos cognitivos de investigação, descoberta e problematização). Se pressupõe, portanto, entre tantas outras coisas, que uma possibilidade, uma capacidade, uma atividade inerente à condição e à experiência humana desde sua infância deva ser domesticada nos limites auto-referenciados de um saber pré-constituído a ser transmitido, por quem o possui, a quem não o possui _e que apenas a transmissão deste saber e dos métodos, hábitos e procedimentos que lhe são próprios, à criança, ao jovem ou mesmo ao adulto, seria capaz de habilitá-lo progressivamente a "pensar corretamente".

Tudo isso como se a possibilidade, a necessidade, a vontade, a liberdade e a capacidade de pensar inerentes à condição humana, como se a experiência humana comum a todos e a todas não fosse o lugar comum e concreto donde brotam e para onde retornam todas as questões, todas as possíveis respostas e própria possibilidade de verificar sua verdade _ou como se alguém pudesse ensinar um outro a pensar _ou como se algo, ou alguém pudesse delimitar as condições desde as quais deve se pensar, ou desde as quais deve-se determinar as condições de verificação da verdade de um pensamento ou de uma proposição. Tudo isso como se alguns soubessem pensar, outros não, e como se os que sabem devessem ensinar aos que supostamente não sabem, bem como verificar se aprenderam ou não. Tudo isso como se a filosofia, ou o próprio pensamento fosse algo distinto e/ou superior à ação e ao movimento autonômo de uma potência criativa que, na medida em que formula suas perguntas e hipóteses, a partir de sua própria experiência, busca verificá-las, junto com outros, em sua verdade ou falsidade _ ou como se a disciplina própria à filosofia fosse de natureza distinta ou 
extrínseca da disciplina que nasce das exigências que nos colocam o pensamento no devir de sua própria auto-realização.

Proponho que se faça o movimento inverso, como caminho para a emancipação intelectual _ fundada na confiança em sua própria capacidade de aprender _e como condição de toda filosofia, de toda educação e de toda comunicação (dialógica) que não se limitem simplesmente a reproduzir os pressupostos estruturais da ordem social desigualitária.

Primeiramente, é preciso que não se suponha nada no processo educacional e cognitivo senão a existência de uma capacidade comum de formulação, verificação e produção dos conceitos que possam elucidar, desde sua origem, as condições reais de nossa própria existência comum _e que se busque os meios pelos quais essa capacidade comum pode ser desperta, exercitada e estimulada até os limites de suas próprias possibilidades.

Que se parta, portanto, da experiência de cada um e da própria experiência comum de todos e de todas como o próprio lugar de verificação dialógica da verdade ou falsidade, da consistência ou inconsistência das proposições de pensamento. O método é relativamente simples: que se tome qualquer fato, qualquer texto, ou qualquer afirmação como passível de ser examinada $e$ verificada em seus pressupostos e efeitos de verdade e poder _e que se faça da aventura compartilhada desta verificação e de sua capacidade de problematização, de produção de conceitos e de formulação e verificação de suas razões e argumentos o próprio caminho do pensamento.

Nesse percurso, deveríamos aprender a nos guiar pela máxima contida nesta proposição de Adorno:

O mero questionamento de como se ficou assim já encerraria um potencial esclarecedor. Pois um dos momentos do estado da consciência e da inconsciência daninhos está em que seu ser assim _ que se é de um determinado modo e não de outro _é apreendido equivocadamente como natureza, como um dado imutável, $e$ não como resultado de uma formação. [10]

\section{A Crítica Emancipatória}

$\mathrm{Na}$ articulação recíproca de todos esses primados, o primado da razão contemplativa impera como o que designa a condição, o estatuto e os próprios limites do pensamento.

O pressuposto de que o pensamento, de que a filosofia seja e deva ser uma atividade eminentemente contemplativa é tomado como uma evidência que sequer deve ser posta em discussão; ela se expressa no próprio mito fundador da filosofia e da ciência ocidentais, que remonta a Platão e Aristóteles, e segundo o qual a condição e a garantia da verdade e da universalidade das proposições, dos enunciados e do próprio conhecimento seria o seu caráter "desinteressado" pressuposto correlato ao da "autonomia das idéias", direta ou indiretamente 
articulado com os demais pressupostos e primados que viemos examinando ao longo desse artigo.

Ora, verdade e conhecimento são necessariamente "interessados".

Por um lado, necessitamos de conhecimentos instrumentais e os produzimos porque precisamos assegurar a produção e a reprodução cotidiana de nossa própria existência pelo trabalho social; para isso, é preciso controlar nosso ambiente para assegurar nossa própria sobrevivência.

Por outro lado, conhecimentos de natureza moral, política, antropológica ou filosófica nascem da própria vida social coletiva, como expressões das práticas, interesses e posições que são capazes de articular suas concepções de mundo no interior de uma formação social.

De um modo ou de outro, pensar é de nosso próprio interesse; o pensamento, em sua historicidade, é uma condição inerente ao tipo de espécie biológica que somos _ ou que nos tornamos. Poderíamos dizer, portanto, que pensar é um interesse e, ao mesmo tempo, uma condição constitutiva da espécie; nesse sentido, a clássica formulação aristotélica segundo a qual o pensamento seria inerente à natureza humana deveria ser entendida no sentido de que a necessidade e o interesse em pensar são inerentes às condições naturais, históricas, sociais e existenciais de existência da própria espécie humana.

Os interesses são, portanto, constitutivos de nosso conhecimento, e não obstáculos a ele.

Nesse registro, podemos argumentar que há interesses que ameaçam nossas próprias necessidades fundamentais como espécie _ $e$ interesses que buscam remover essas mesmas ameaças.

Do mesmo modo, deveríamos poder reconhecer que há interesses que tomam como premissas de seus próprios argumentos a racionalização das relações de força, poder e dominação que organizam a produção da vida pela própria vida, o trabalho social, as formações sociais e o processo civilizatório como um todo _e que poderíamos chamar de ideológicos, já que desse modo eles escondem na mesma medida em que expressam, racionalizam e buscam articular interesses de classe _e interesses que buscam organizar o pensamento e a produção de conhecimento precisamente do ponto de vista da elucidação dos modos pelos quais essas relações de força, poder e dominação organizam não apenas o processo civilizatório como a produção da consciência, dos conceitos e dos enunciados que funcionam como categorias, ou como expressões ideais de uma ordem social de dominação.

Como diria Habermas, deveríamos poder reconhecer que o oposto da "ideologia" não é a verdade, o conhecimento ou a ciência, "mas essa forma particular de racionalidade 'interessada' que chamamos de crítica emancipatória" $\lfloor 11]$. 
Há certas formas de conhecimento de que precisamos a todo custo para ser livres, e uma crítica emancipatória, como o marxismo ou o freudismo (sic), é simplesmente qualquer forma de conhecimento que seja a necessária no momento. Nesse tipo de discurso, "fato"(cognição) e "valor"(interesse) não são realmente separáveis: o paciente em psicanálise, por exemplo, tem interesse em embarcar num processo de auto-reflexão porque, sem esse tipo de conhecimento, permanecerá aprisionado na neurose ou na psicose. De modo paralelo, um grupo ou classe oprimida, como vimos no pensamento de Lukács, tem interesse em chegar a compreender sua situação social, já que, sem esse autoconhecimento, continuará a ser vítima dela.

Tudo isso nos obrigaria a reconhecer na identificação dos interesses, das premissas e dos efeitos de verdade e poder produzidos por um determinado enunciado, conceito ou teoria como a condição e a tarefa da crítica emancipatória _ na mesma medida em somos levados a reconhecer na produção de práticas, conceitos $e$ formulações dotados de potência emancipatória a condição e a tarefa fundamental de toda crítica emancipatória.

\section{A Necessária Politização do Pensamento e da Vida Cotidiana}

A crítica emancipatória exige, portanto, como sua própria condição, a politização do pensamento e da própria vida cotidiana.

Politização quer dizer aqui: poder mostrar que todas as ações, práticas, interesses, relações, enunciados, fenômenos e acontecimentos expressam e articulam um determinado modo de produção e reprodução dos vínculos humanos, do estarjunto humano; portanto, um determinado modo de produção da vida pela própria vida, um determinado modo de organização do trabalho social, das relações de produção, das relações sociais e de todas as atividades produtivas pelas quais a vida humana se realiza _e consequentemente, não só uma determinada política da verdade e da produção da "verdade", não só uma determinada organização dos mecanismos de decisão política, não só uma determinada organização dos modos de produção, exercício, circulação e reprodução do poder e das práticas e relações de poder, como, em tudo e por tudo isso, uma determinada política da vida cotidiana, uma determinada política de constituição, socialização e subjetivação dos sujeitos sociais e de todas as práticas, valores, relações e instituições em que eles se formam e são chamados a se reconhecerem e se interpelarem mutuamente como sujeitos.

Mais precisamente, politização quer dizer: poder demonstrar como isso que vivemos, chamamos e reconhecemos como "real", sua experiência, conhecimento e consciência se produzem e se organizam, em sua historicidade própria, a partir de um certo modo de produção e reprodução dos vínculos humanos, do estar-junto humano; e na mesma medida, poder demonstrar como o que reconhecemos como o "sujeito do real" vem a se constituir e se organizar sempre, na historicidade de sua produção desejante, afetiva, significante e cognitiva, no interior de um determinado modo de produção e reprodução da vida comum, do trabalho social, da 
linguagem, do conhecimento, da comunicação e das relações sociais que aí se formam.

A politização se mostra assim como condição da cognoscibilidade efetiva de tudo o que é humano, já que é nela e por ela que as condições de constituição e existência do "real", do "humano" e de sua experiência podem ser pensadas em sua historicidade própria, desde sua gênese, desde suas premissas, mecanismos e efeitos de verdade e poder_o que por sua vez nos previne de tomar essas mesmas condições, apoliticamente, acriticamente e ahistoricamente, como se fossem elas as próprias condições gerais de toda existência e de toda realidade.

O sentido político do conhecimento está em que nele, como já dissemos antes, chega a se formular, se expressar e se racionalizar a consciência uma práxis determinada; está em que nele e em torno dele se organiza e se expressa todo um modo de produção da vida; está em que nele e em torno dele se organiza, portanto, não só uma concepção de mundo, um sentimento, uma experiência e uma consciência do mundo, como um determinado modo de existir, de agir e de conceber a própria existência.

Poderíamos nesse sentido dizer que não há nada que não seja político (na verdade, um outro modo de dizer que não há nada que não seja histórico; até mesmo o que chamamos, ou podemos chamar de "natural", como o desejo, se organiza numa determinada forma de sua produção e de sua organização, a partir de determinadas premissas, em função de certos mecanismos e com determinados efeitos que deveríamos poder reconhecer como políticos no sentido em que aqui definimos esse termo). E se não há nada que não seja político, se não há e não pode haver ação, relação, procedimento, produção ou realidade que não sejam eminentemente políticos, não há conhecimento que não seja ele mesmo político, tanto em sua origem como nos efeitos que dele advém.

Politização, nesse sentido, é o trabalho comum que se efetua a partir e em torno da consciência da realidade e da sociedade, da subjetividade e da própria vida cotidiana como fatos políticos; como atividade de uma práxis e uma consciência determinadas, ela é a condição necessária para a formação e constituição de sujeitos sociais efetivamente capazes de problematizarem as condições reais de sua existência; de sujeitos efetivamente capazes, portanto, de tomarem sobre si a tarefa comum de tornar o próprio mundo consciente de suas ações e das condições de sua existência _ e nesse sentido, efetivamente capazes de gerar as condições subjetivas e objetivas para sua transformação.

\section{Para Não Concluir}

Em sua obra filosófica, Marx se empenha em elucidar as premissas e conseqüências teóricas, práticas, políticas, éticas, pedagógicas, existenciais e filosóficas que podem vir a ser extraídas do fato fundamental de que é rigorosamente impossível que o pensamento se limite a ser uma mera contemplação do real _ e desse trabalho nasce não só toda uma outra formulação 
da condição e do estatuto, do sentido e da tarefa fundamental do trabalho de pensamento, como toda uma tradição filosófica que se constrói a partir dela.

A formulação em que tudo isso chega a se condensar filosoficamente na forma de um enunciado fundamental (a célebre décima-primeira tese contra Feuerbach). Ele nos diz que

Os filósofos se limitaram até aqui a interpretar o mundo de diversas formas; cabenos agora transformá-lo.

Nesse enunciado, se nos coloca decisivamente um desafio, ao mesmo tempo prático e teórico, ético e político, pedagógico, existencial e filosófico;

silenciosamente, ele tem nos conduzido desde o começo desse texto, antes dele e para além desse e de todos os outros que possam existir; suas exigências, tarefas, desdobramentos e conseqüências transbordam não só esse texto, como todos os textos.

Como enunciado de uma práxis, sua verdade e seu critério de verdade só podem estar na própria práxis.

Com isso, não concluímos; pelo contrário, nos vemos agora obrigados a retornar em outro momento ao problema aqui colocado, não mais para designar a origem, os limites e o modo de funcionamento da filosofia como razão disciplinar, ou como razão imperial, mas para começar a pensar as práticas e as categorias próprias de uma filosofia da práxis e os desafios que ora nos coloca a crítica emancipatória num mundo cuja mera reprodução, no médio e longo prazo, das condições de sua existência é rigorosamente incompatível com a preservação das mínimas e mais elementares condições, ecológicas e sociais, de reprodução da própria vida na Terra.

\section{Referências}

Adorno, Theodor, Educação e Emancipação, Ed. Paz e Terra, S. Paulo, 2000.

Althusser, Louis, Ideologia e Aparelhos Ideológicos de Estado (Notas para uma Investigação), in O Mapa da Ideologia, (org.) Slavoj Zizek, Contraponto Editorial, 1996

Aristóteles, La Metaphysique, (introduction, notes et index par Jean Tricot), Librairie Philosophique Jean Vrin, Paris, 1986

Eagleton, Terry, A Ideologia e suas Vicissitudes no Marxismo Ocidental, in O Mapa da Ideologia, (org.) Slavoj Zizek, Contratempo Editorial, 1996.

Foucault, Michel, Em Defesa da Sociedade, Ed. Martins Fontes, S. Paulo, 2000

Foucault, Michel, Microfísica do Poder, Ed. Graal, Rio de Janeiro, 1985 
Freire, Paulo, Pedagogia do Oprimido, Ed. Paz e Terra, S. Paulo, 2003

Gramsci, Antonio, Cadernos do Cárcere, (seis volumes), Editora Civilização Brasileira, Rio de Janeiro, 2001

Habermas, Jürgen, The Theory of Communicative Action, 2 vols., Boston, MA, 1984

Lukács, Georg, Histoire et Conscience de Classe, Les Éditions de Minuit, Paris, 1960

Marx, Karl, A Ideologia Alemã, Ed. Martins Fontes, S. Paulo, 2000

Marx, Karl, Teses contra Feuerbach, in Os Pensadores, Ed. Abril, S. Paulo, 1978

Mészáros, István, Para Além do Capital, Boitempo Editorial, S. Paulo, 2002

Nietzsche, Friedrich, Jenseits von Gut und Böse, Alfred Kröner Verlag, Stuttgart, 1991

Rancière, Jacques, O Mestre Ignorante, Ed. Autêntica, Belo Horizonte, 2002

* PROFESSOR DO DEPARTAMENTO DE FILOSOFIA - UnB

Para publicar nos Cadernos Cratilo, consulte www.unb.br/ih/fil/cratilo. As regras:

1. Podem publicar no Cratilo sem apelo a comissão editorial as seguintes pessoas: todos os docentes do FIL, todos os estudantes do mestrado, todos os palestrantes do SIP-FIL.

2. Podem publicar no Cratilo os estudantes de graduação que tiverem seus textos de dissertação filosófica recomedados para Cratilo pela banca (neste caso a comissão editorial apenas referendaria a decisão da banca).

3. Outras pessoas poderão submeter textos à comissão editorial.

[1] Os pensamentos da classe dominante são também, em todas as épocas, os pensamentos dominantes; em outras palavras, a classe que é o poder material dominante numa determinada sociedade é também o poder espiritual dominante. A classe que dispõe dos meios de produção material dispõe também dos meios da produção intelectual, de tal modo que o pensamento daqueles aos quais são negados os meios de produção intelectual está submetido também à classe dominante. Os pensamentos dominantes nada mais são do que a expressão ideal das relações materiais dominantes; eles são essas relações materiais dominantes consideradas sob forma de idéias, portanto a expressão das relações que fazem de uma classe a classe dominante; em outras palavras, são as idéias de sua dominação (Marx, A Ideologia Alemã, p.48) 
[3] É toda essa materialidade da ideologia que mais tarde Althusser vai problematizar em sua investigação dos Aparelhos Ideológicos de Estado, e Foucault vai investigar, em sua microfísica do poder, sob os conceitos de disciplina, controle, biopoder e biopolítica.

[4] As premissas estruturais do regime do capital, de seu processo civilizatório, de todo o seu modo de produção e reprodução social, de sua historicidade e do que Marx pensou como sua "subjetividade única e global" podem ser analiticamente discriminadas na formulação que se segue (que sem pretender ser exaustiva, se limita a destacar as determinações fundamentais de todo o metabolismo social do capital): a) a propriedade privada dos meios de produção e o direito inviolável à acumulação privada de capital, como direito à expropriação privada do trabalho comum e da riqueza socialmente produzida, como princípio de uma ordem social de dominação e como fim teleologicamente determinado de todo um sistema econômico e social; b) divisão da sociedade, como sociedade de classes, entre os proprietários dos meios de produção e todos que, para reproduzir sua própria existência, dispõem apenas de sua força de trabalho, a ser alienada como mera mercadoria; consequentemente, a existência concretamente histórica da luta, ou da guerra de classes sob todas as suas formas e disfarces, como expressão inelutável do antagonismo fundamental sobre o qual se baseia o metabolismo social; c) o imperativo do lucro, configurado no direito à expropriação dos trabalhadores pelos proprietários dos meios de produção; em outras palavras, o direito à apropriação privada do trabalho social para fins de acumulação de capital, que Marx caracterizou como extração de mais-valia, e que funciona como determinação fundamental do modo de produção e como condição de possibilidade da acumulação capitalista; d) a pluralidade concorrencial dos capitais, em que a competitividade em estado puro se materializa como princípio agenciador, articulador e regulador da economia, da sociabilidade, dos processos de acumulação e da natureza das relações entre todos os agentes do sistema, sejam eles indivíduos, grupos, empresas, regiões, nações, etc,... O que se expressa na formulação clássica de Adam Smith, segundo a qual o princípio regulador do sistema está em que todos os agentes individuais, numa perpétua luta de todos contra todos, devem buscar realizar seus interesses egóicos e maximizar suas vantagens por quaisquer meios a seu alcance, o que a seu ver produziria automaticamente o bem geral, entendido por ele como a maximização constante da capacidade de produção e acumulação de riquezas; e) a tendência, inata ao processo de reprodução e acumulação de capital, no sentido da expansão $e$ potenciação contínua, indefinida e exponencial de todos os meios, padrões e regimes de produção, consumo e acumulação, num ambiente ele mesmo finito; f) tendência à subordinação, à reificação e à instrumentalização sistemicamente determinada da vida de homens e mulheres, de seu trabalho, de sua atividade e de sua capacidade produtiva, do conhecimento e da ciência, da política, das leis, normas e instituições, do Estado, de seus aparelhos coercitivos e ideológicos, de todos os aspectos da reprodução social e da própria natureza em geral, tomados seja como meios, objetos, mercadorias, recursos, insumos, valores, instâncias ou funções do processo de reprodução e acumulação de capital; g) tendência a 
consagrar a racionalidade instrumental _ determinada pela produção e adequação dos meios a fins determinados _ como racionalidade em geral, como racionalidade hegemônica, ou até mesmo como racionalidade natural; produção e reprodução de um regime de racionalidade social e política, de um senso comum e de um regime de produção e reprodução de saberes hegemonizado pela racionalidade instrumental, que coincide com a própria racionalidade do capital, do mundo, do conhecimento $e$ da sociabilidade que se configura à sua própria imagem $e$ semelhança; h) a separação necessária e hierarquicamente determinada entre a vida, o trabalho e o comando que, de fora, sobre eles se exerce; separação necessária entre o sujeito e o objeto do comando, que se desdobra como princípio político de organização da produção e das relações de produção, de todos os setores da vida social e de todos os âmbitos da atividade produtiva humana e se internaliza na realidade e na consciência social como princípio constituinte da sociabilidade, da política da vida cotidiana, da lei e da normatividade social, das instituições e relações sociais e da própria produção hegemônica de subjetividade, consciência, cognição e comunicação; i) alienação do trabalho e do trabalhador, como alienação/expropriação do produto e do valor de seu próprio trabalho e das condições de determinação de sua produção e apropriação; como alienação de sua atividade e capacidade produtiva; como alienação de sua relação consigo, com os outros e com a própria natureza; em suma, como alienação/expropriação de seu próprio ser, que não é senão sua energia, sua atividade, sua capacidade produtiva, que não existe, não se desdobra e não se expressa senão como sua própria atividade, como a produção de sua própria vida; j) formação de uma sociedade e de todo um processo civilizatório em que seus mecanismos de produção $e$ apropriação de riquezas e tomada de decisões políticas tendem a escapar a qualquer controle social; determinados e regulados no marco de uma sociedade e de um estado de classe, eles acabam por ser capturados, agenciados, sobredeterminados e hegemonizados, através das mias diversas mediações, pelas premissas estruturais do regime do capital.

Essas premissas, em sua articulação recíproca, em suas implicações, produtos, efeitos e subdivisões possíveis, respondem pela estrutura, pela lógica e pelo metabolismo social geral do regime do capital. Elas constituem a subjetividade única e global do capital, suas mediações histórico-sociais, sua atividade própria e sua capacidade de captura, agenciamento e sobredeterminação do processo de reprodução social em sua totalidade.

Por si sós, elas ainda nos dizem nada, diretamente, sobre o modo a subjetividade única e global do capital é capaz de hegemonizar todos os setores da vida social e todos os âmbitos da atividade produtiva humana, inclusive a própria produção de conhecimento, a própria educação, a própria filosofia.

[5]Por um lado, como veremos, a questão pela filosofia não se encerra no problema específico da filosofia; por outro, problemas relativos à filosofia e a seu ensino e produção, como a relação da filosofia com sua história, o papel da doxografia, a relação da filosofia com outros saberes, etc., não serão aqui diretamente abordados; trata-se aqui de elucidar a lógica subjacente ao funcionamento da filosofia como razão disciplinar; portanto, apenas explicitaremos as premissas fundamentais a partir das quais a discussão desses temas específicos pode aflorar e desenvolver-se na perspectiva de um questionamento decisivo pelo 
modo como funciona a filosofia no interior da razão disciplinar, do aparato universitário e de toda s série de condições extra-discursivas que definem as condições de sua existência e realização.

[6] Michel Foucault, Em Defesa da Sociedade, ps.220/221

[7] Foucault, ibidem

[8] Michel Foucault, Microfísica do Poder, p.14.

[9] As observações que se seguem se inspiram na leitura de O Mestre Ignorante, de Jacques Rancière (2002), e também, é claro, nas luminosas perspectivas que pode abrir a leitura da obra de Paulo Freire.

[10] Adorno, Theodor, Educação e Emancipação

[11] Eagleton, Terry, "A Ideologia e suas Vicissitudes no Marxismo Ocidental", in O Mapa da Ideologia, (org. Slavoj Zizek. 